\title{
Evaluating the Effectiveness of Electronic Medical Records in a Long Term Care Facility Using Process Analysis
}

\author{
Barbara Cherry ${ }^{1, *}$, DNSc, MBA, RN; Ken Carpenter $^{2}$, MS, LNHA \\ ${ }^{1}$ Texas Tech University Health Sciences Center, Lubbock, Texas, USA \\ ${ }^{2}$ Christian Care Centers, Mesquite, Texas, USA
}

Submitted July 2010. Accepted for publication November 2010.

\begin{abstract}
This study was conducted to determine the effect of the electronic medical record (EMR) system on work process efficiencies in a long-term care facility. A pre-post intervention study design was used with process flow analysis conducted as part of the data collection methodology. Work processes were measured through direct observation and recording of steps taken as nurses completed their daily work. Observed work processes were documented in the form of process flow charts. Process flow charts detail every step in a process and provide a unique and accurate method of evaluating the impact that EMR systems have on work flow in the healthcare setting. The study demonstrated that the EMR can lead to a reduction in the number of steps required to complete several daily work processes, allowing nurses the opportunity to dedicate more time to direct care of the facility's residents and thus contribute to improved quality care.
\end{abstract}

Keywords: long-term care, nursing home, electronic health record, process flow analysis

\section{INTRODUCTION}

Providing high quality, financially sustainable institutional long-term care (LTC) services for a frail elderly population will become increasingly difficult over the next decade and beyond as the nation faces a growing population of senior citizens, strained state and federal budgets, and serious LTC workforce challenges. The Baby Boomer population will surge past 65 years old over the next decade. With predictions that $35 \%$ of all individuals over the age of 65 will eventually require nursing home care [1], state Medicaid budgets - the primary payer for long-term care in the United States will be burdened to meet this rising demand for services.

In addition to the rising demand for nursing home care and fiscal challenges, the difficulty of maintaining a competent and enthusiastic LTC workforce is well

*Corresponding author: Professor Barbara Cherry, Texas Tech University Health Sciences Center, 3601 $4^{\text {th }}$ Street, Lubbock, Texas 79430. Barbara.cherry@ttuhsc.edu. The other author: kcarpenter@cccinc.net. 
documented. High staff turnover and vacancy rates are commonplace in nursing homes. Recruiting highly competent nurses and paraprofessionals to the nursing home environment is becoming increasingly problematic. The instability of the LTC workforce is responsible for serious safety and quality of care issues, excessive costs due to the need to continuously recruit and train new employees, and excessive workloads and inadequate supervision for nurses and nurse aides [2]. Experts from the National Commission for Quality Long-Term Care report that "as a result of the growing demand from aging baby boomers and a shrinking of the traditional caregiver labor pool, the future will be immeasurably worse without decisive action by both the public and private sectors" (p. 1) [2].

The issues affecting quality institutional LTC will require innovative changes to impact the cost of care, quality of care and the workforce concerns. Introducing new technology holds promise for cost savings, improving quality and improving job satisfaction for nurses and nurse aides [2,3]. Specifically, information technology (IT) is recognized for improving the safety, quality and efficiency of healthcare $[4,5,6]$. The electronic medical record (EMR), an essential component of the healthcare IT infrastructure, holds significant potential for contributing to cost reductions, increased efficiency and improved care quality in LTC facilities. While acute care providers have been active in the EMR initiative for many years, the use of EMRs by LTC providers is a more recent development.

There has been strong evidence to support the benefits gained from EMRs in acute care settings and physician practices. Such benefits include improvements in clinical outcomes, clinical decision making, communication with patients and other providers, medical error prevention, access to medical records, and adherence to clinical guidelines $[6,7,8]$. In a systematic review of the impact of health IT on quality, efficiency, and costs, researchers reviewed 257 studies and reported the following major benefits:increased adherence to care based on clinical guidelines with the most notable improvement in preventive health; decreased medication errors; improved quality through surveillance and data aggregation capabilities (i.e., infection surveillance systems); and decreased utilization of care by reducing or eliminating redundant or inappropriate care [6].

Although there is strong evidence to support the benefits of health IT, some experts have questioned the applicability of this evidence to the broader medical community because most studies were conducted largely in academic medical centers $[6,9]$. One study analyzed four years of nationally representative data from Medicare, which is the primary health insurance coverage for persons aged 65 years and older or disabled in the United States. The Medicare data analysis found that the effect of the EMR on patient safety was small but improved over time and suggests that investments in healthcare IT must be accompanied by a strong evaluation component [9]. Chaudhry and colleagues [6], in their systematic review of the effect of IT on quality, efficiency and costs of health care, suggest that more studies are needed to evaluate commercially developed systems in community settings because the majority of studies reviewed have been conducted in major academic medical centers. 
As the healthcare community moves forward with adoption of health IT and EMR systems, implementation processes remain complex and problematic. The primary barriers to EMR implementation in acute care and physician practice settings are implementation costs, uncertainty about the return on investment, concerns about maintenance costs, and lack of physician acceptance [8, 10-13]. Similarly, costs and lack of industry standards have been identified as barriers in the LTC setting [3]. Other barriers to EMR implementation include software issues such as lack of an efficient way to view the overall picture of patient progress and care, lack of automatic prompts, and poor system navigability [14]. The lack of technical expertise in information technology has been identified as a barrier in hospital and physician practice settings $[8,10,12,13]$ as well as the LTC setting [3]. Other barriers to the implementation of EMRs in LTC facilities include costs, training, complex implementation processes, and the lack of evidence that such systems can deliver the promised benefits [3].

The primary facilitators to successful EMR implementation in acute care and physician practice settings include strong leadership support, strong implementation planning, integration of new routines with the current workflow, and realistic goals and expectations $[13,15]$. Facilitators to successful EMR implementation in the LTC setting include strong implementation planning, initial and follow-up training programs, and knowledge that EMR systems will have quantifiable benefits in both care quality and financial outcomes [3].

Implementation of health IT systems may have a significant impact on clinical workflow and possibly impact safety, quality, and efficiencies in the clinical setting $[16,17]$. Evidence of unintended adverse consequences resulting from implementation of computerized provider order entry systems include ergonomic issues that disrupt workflow [16, 17], difficulty in accessing patient information from different systems that are not integrated [16], systems designed for one specific discipline (i.e., physicianfocused vs. designs to support all clinical staff) [16], reduced ability to have full information regarding the patient's situation [16], and changes in the way the clinician and patient interact [17]. Studies identifying workflow issues related to health IT systems are important to gain insight about how to mitigate problems and improve system design [17]. With the knowledge that more evidence is needed related to the impact of IT systems in LTC environments, representatives from an LTC company, a university health sciences center, a state department of aging and disability services, and an EMR vendor partnered to conduct a year-long evaluation study of a web-based EMR system.

\subsection{Features of the EMR System}

The EMR system implemented in this evaluation is web-based and designed specifically for the LTC industry. The system is pass-word controlled with accessibility to various functions within the system determined by the staff member's role. The system includes typical LTC functions such as the Minimum Data Set (MDS) with online reporting, care planning, nurses notes, vital signs, assessment and progress notes for all disciplines, physician order management, and census management. The system also offers protocol-based event management, automated communication and 
reminders, lab and pharmacy integration, and physician communication systems. For example, the system is designed so that when a resident event occurs (e.g., fever, fall, etc.), the nursing assessment is conducted, documented electronically according to facility protocols, and may be sent electronically to the physician via his/her electronic communication mode. The system allows for physician orders to be sent electronically to the pharmacy, lab, x-ray or other vendors. The system incorporates the highest practical levels of security and encryption along with features to ensure compliance with the Health Information Portability and Accountability Act (HIPAA).

\subsection{Study Purpose}

The purposes of the study were to determine the effect of the EMR system on resident outcomes, nursing satisfaction, costs and reimbursement, and work process efficiency. This report focuses on the results related to work process efficiency. The study received Institutional Review Board approval prior to implementation.

\subsection{Research Question}

The research questions were developed through a group process with representatives from each of the partnering organizations. Based on expert reports that IT in LTC may improve the quality and efficiency of care, reduce costs, and increase staff retention $[18,19],{ }^{4}$ the partners identified resident outcomes, nursing satisfaction, costs and reimbursement, and work process efficiency as the four core areas in which to develop research questions. While the overall scope of the study addressed these four core areas, the purpose of this article is to report on the work process evaluation.

The research question related to work process efficiency was: What changes occur in process flow charts completed one month prior to implementation of the EMR system compared to process flow charts completed after full implementation of the system for work processes of: (a) transcribing and completing physicians' orders; (b) transcribing and completing medication orders; (c) transcribing and transmitting ancillary orders; (d) transferring residents to acute care; and (e) processing new admissions to the facility?

\section{METHODS}

A pre-post intervention design was used to evaluate the effectiveness of the EMR system and to answer the research questions. Work process data in the form of process flow charts were collected for the six-month period prior to EMR implementation and then again nine months after full implementation. Data collected in the preimplementation period was used as a baseline for comparisons to the post implementation data. Full implementation encompassed the time period beginning when training of facility staff was initiated and ended approximately nine months later. This nine month time period allowed for the system to become institutionalized in the facility as a routine part of the staff's daily work. Figure 1 summarizes the time line for the project.

The research team anticipated that the EMR system would increase efficiency in those work processes that required documentation by the nurses. To measure work processes, data were collected through direct observation and recording steps in the 


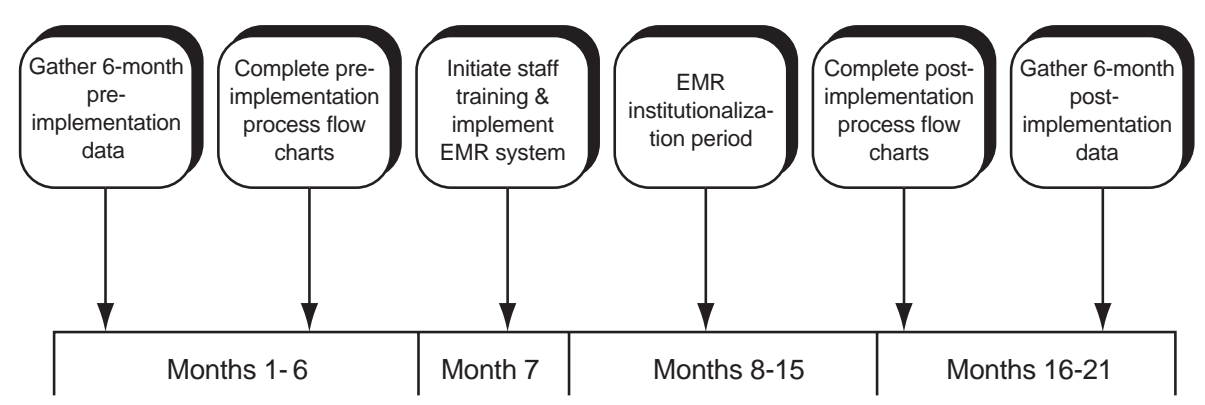

Figure 1. Project timeline.

work processes completed by nurses as part of their daily work. Observed work processes were documented in the form of process flow charts. For the purposes of this study, a process flow chart is defined as a diagram of a series of interrelated tasks that are necessary to result in a specific output. The tasks are presented sequentially and each task is presented in a specific shape in the diagram to indicate if the task is the starting or ending point and if there is a paper or electronic document associated with the task. Because process flow charts detail every step in a process, they provide a unique and accurate method of evaluating the impact that EMR systems have on work flow in the healthcare setting.

\subsection{Sample/Setting}

The study was conducted in a 120-bed LTC facility located on a university health science center campus in West Texas. The facility, which has 60 beds dedicated to specialized dementia care, 40 beds dedicated to residential care, and 20 beds dedicated to skilled nursing care, is a member of a group of ten facilities owned and operated by a not-for-profit, faith-based organization. Participants in the work process flow analysis were selected because of their status as a registered nurse (RN) or licensed vocational nurse (LVN) employed by the facility and working their assigned shift during the time the researcher was present for observations. The selected RNs and LVNs $(\mathrm{n}=20)$ were given informed consent, agreed to participate, and allowed the researcher to observe them throughout their workday for documentation of the steps in work processes.

\subsection{Data Collection and Analysis}

Work process data were collected by direct observation of staff members on duty completing work processes as they occurred throughout the workday. One researcher observed the work processes completed by nurses present on duty for a total of six shifts (three day shifts and three evening shifts) during both the pre-implementation and postimplementation time periods. Steps were recorded and used to develop work process flow charts for each of the following work processes:

1. Transcribing Physicians' Orders: the process followed by the nursing staff to manage occurrences in which the physician ordered a change in the plan of care for a facility resident. 
2. Transcribing Medication Orders: the process followed by the nursing staff to manage a new medication order for a facility resident.

3. Transcribing Ancillary Orders: the process followed by the nursing staff to implement orders for laboratory or radiology tests.

4. Resident Transfer to Acute Care: the process followed by the nursing staff to managed the transfer of a resident from the long-term care facility to the acutecare facility.

5. Resident Admission Process: the process followed by the nursing staff to admit a new resident to the long-term care facility.

Each of the processes listed above were observed a minimum of three times on the day shift and three on the evening shift during both the pre-implementation and postimplementation time periods. Steps in each process were hand recorded on paper in the order in which they occurred. Steps were then converted to a flowchart format using Flowcharter $7 \circledR$ software. Process flow charts were reviewed and verified for accuracy by charge nurses or other appropriate staff members with over one year experience in the facility.

Data analysis consisted of identifying and comparing pre and post implementation the number of a) steps in the process; b) forms or documents used by the nurse to complete the process; and c) times a medication name and dose had to be hand written or typed by the nurse to complete the process. The time to complete each step was not included in the analysis because of the frequent interruptions encountered by nurses during the time they were involved in completing work processes, making time estimates difficult to accurately assess. Such interruptions included urgent phone calls and requests from residents and family members who directly seek out the nurse.

\section{RESULTS}

The analysis of the work process flow charts showed a decrease from pre-EMR implementation to post-EMR implementation for the number of steps required to complete four of the five processes studied. The only process that showed an increase from pre-EMR implementation to post-EMR implementation was for the resident admission process. Table 1 summarizes each of the work processes analyzed and the change in the number of steps observed during the pre and post implementation time periods. Sample process flow charts are included in Figure 2 and Figure 3.

Of particular note regarding the process of transcribing medication orders is that during the pre-implementation time period, nurses handwrote the medication order four different times and handled eight different forms. For this same work process in the post-implementation period, nurses entered the medication order into the computer one time and handled four forms. There is potential for error each time a nurse must handwrite a medication order on a different form. Thus the reduction in writing the medication order from four different times to entering it only one time in the EMR may have a significant impact on improving medication safety.

The process of transcribing physician's orders changed from 29 required steps preEMR to 21 steps post-EMR. Any one step missed in this process has the potential for causing a medical error such as a lab test not being preformed or a specified treatment not being carried out. Thus, just as in the reduction noted in the process for transcribing 
Table 1. Change in steps required to complete work processes

\begin{tabular}{|l|c|c|}
\hline Work Process & Steps: Pre & Steps: Post \\
\hline $\begin{array}{l}\text { 1. Transcribing Physicians' Orders: process followed by the } \\
\text { nursing staff to manage occurrences in which the physician } \\
\text { ordered a change in the plan of care for a facility resident }\end{array}$ & 29 & 21 \\
\hline $\begin{array}{l}\text { 2. Transcribing Medication Orders: the process followed by the } \\
\text { nursing staff to manage a new medication order for a facility } \\
\text { resident }\end{array}$ & 19 \\
\hline $\begin{array}{l}\text { 3. Transcribing Ancillary Orders: the process followed by the } \\
\text { nursing staff to implement orders for laboratory or radiology } \\
\text { tests }\end{array}$ & 14 & 11 \\
\hline $\begin{array}{l}\text { 4. Resident Transfer to Acute Care: the process followed by the } \\
\text { nursing staff to manage the transfer of a resident from the } \\
\text { long-term care facility to the acute-care facility }\end{array}$ & 14 \\
\hline $\begin{array}{l}\text { 5. Resident Admission Process: the process followed by the } \\
\text { nursing staff to admit a new resident to the long-term care } \\
\text { facility }\end{array}$ & 16 paper & 13 paper \\
\hline $\begin{array}{l}\text { 6. Required medical record documentation: number of forms } \\
\text { or documents a nurse must complete during one shift }\end{array}$ & 3 electronic \\
\hline
\end{tabular}

medication orders, the reduction in the steps has the potential to improve resident safety and reduce medical errors.

While steps in the process to transfer a resident from the nursing facility to an acute care setting were only reduced by one step post-EMR, the time savings may be more significant. In the pre-EMR stage, one step is to copy portions of the resident's medical record to be sent to the acute care facility. Pulling certain parts of the paper medical record, walking to the copy machine located in a part of the facility away from the nursing unit, and manually feeding through the copy machine is more time consuming when compared to clicking on the computer screen to print the required medical records while the nurse remains on the nursing unit.

Overall, the number of steps required to complete the various work processes decreased with the use of the EMR system. As discussed above, the potential for additional benefits related to safety and care quality are significant along with the reduction in the number of steps in work processes.

\subsection{Additional Findings}

During the time spent by the researcher in the facility, other observations were made that merit further discussion. When performing daily charting, the nursing staff was able to move from one resident's record to another very quickly using the EMR system. Before implementation of the system, the nurse would collect a chart from the chart rack, complete charting, return to the chart rack, then find the next chart, and so on throughout the day. Frequently, time was spent looking for charts since many other 


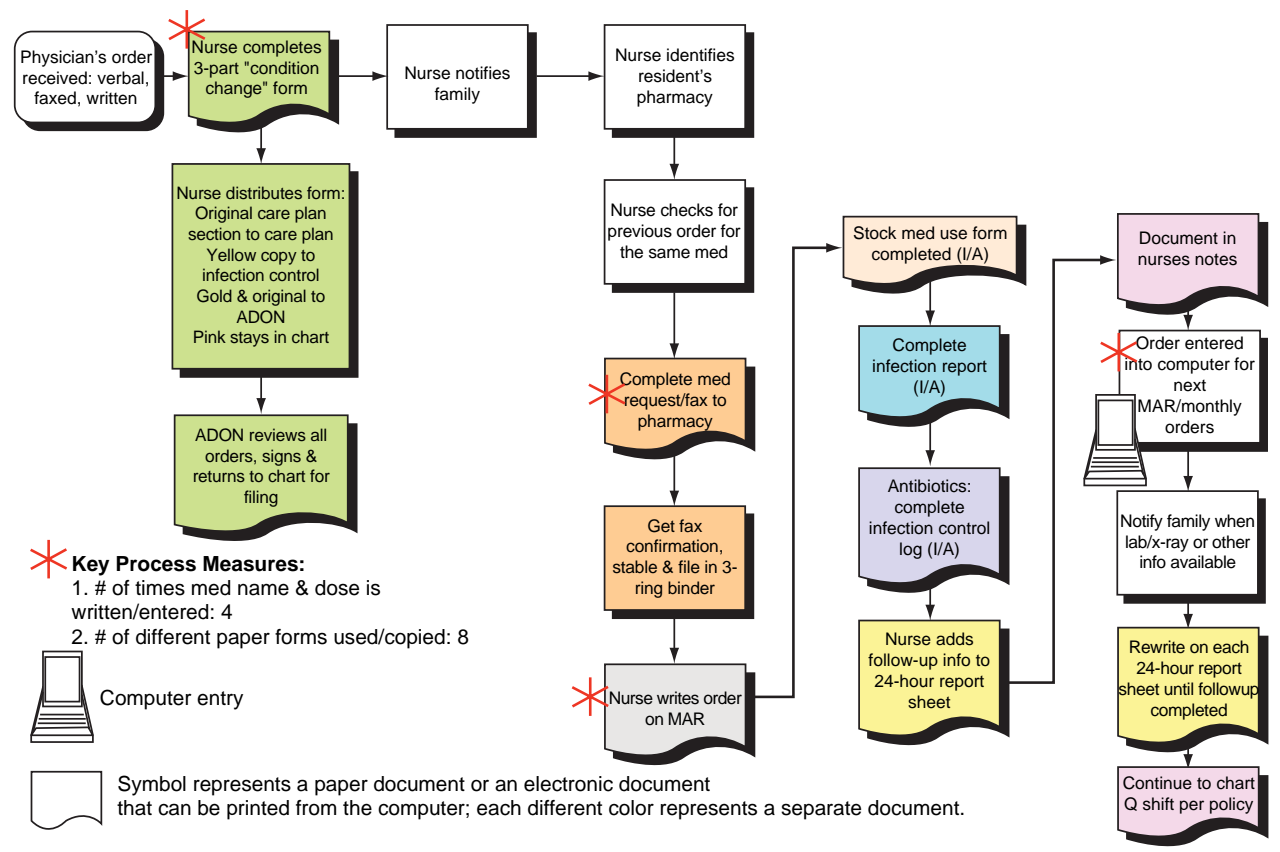

I/A: If applicable

Figure 2. Transcribing medication orders: PRE-implementation.

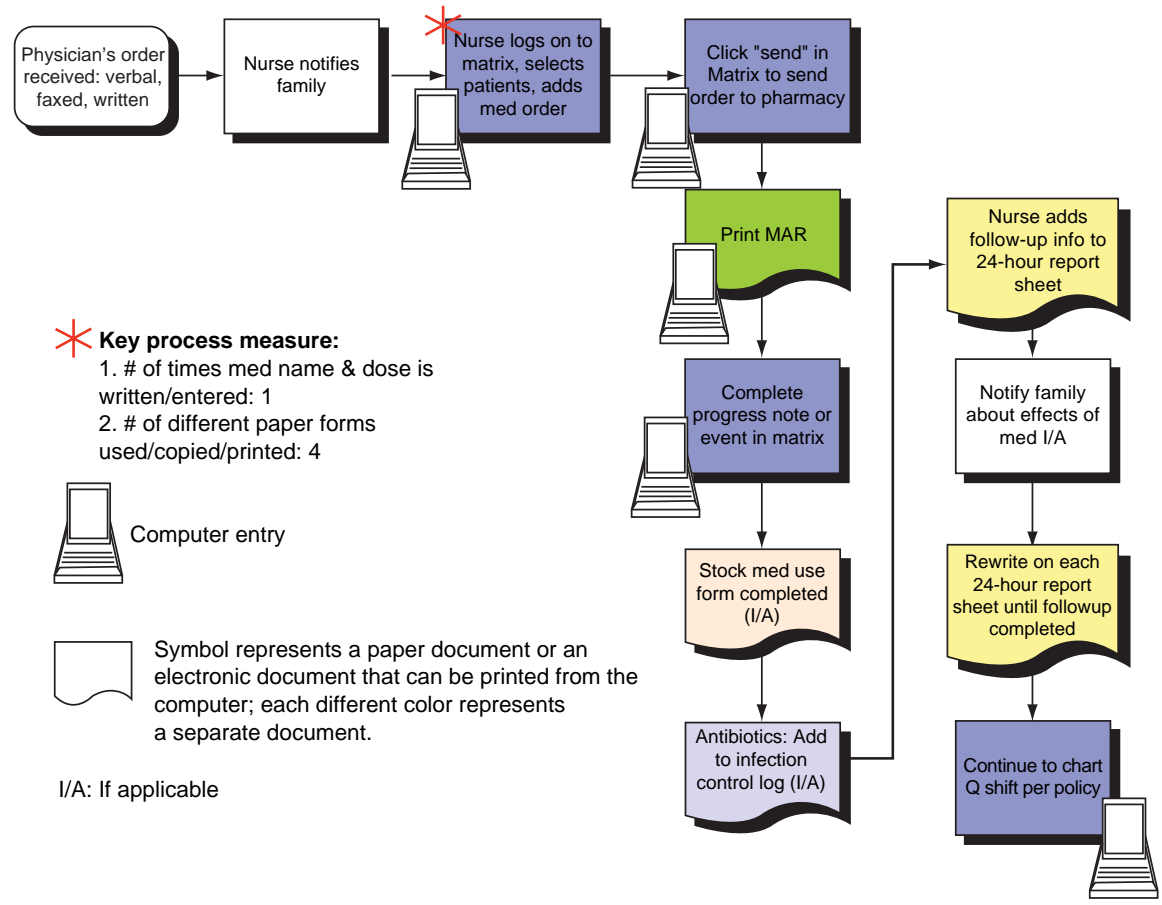

Figure 3. Transcribing medication orders: POST-implementation. 
staff members also used the charts (e.g., social worker, dietitian, pharmacist, nursing director, therapists, providers, and health professions students). Using the EMR, multiple staff members could review and document in residents' records at the same time, thus increasing efficiency for all staff members.

The availability of the EMR on each staff member's desk top computer facilitated his/her ability to provide prompt information to residents' families. For example, when a family member came in to speak with the social worker, the social worker was able to immediately access the resident's records rather than walking to the nursing unit to find the chart. Additionally, lap top computers were used during care plan and medical meetings and facilitated accessing needed resident information rather than going to the nursing unit to find charts.

\subsection{Limitations}

The investigators acknowledge that generalizations of study results are limited because of the pre-post study design and lack of a control group. While the pre-post design cannot determine whether the results are solely due to the EMR intervention, it can help identify the most promising changes and determine areas for more rigorous study.

An additional limitation related to the inability to assess the time to complete the work processes before and after implementation of the EMR system. While the researchers acknowledge the time to complete work processes is an essential component of efficiency, it was not possible to assess time accurately because of the frequent interruptions encountered by nurses during the completion of a work process.

\section{DISCUSSION}

The LTC industry has a strong incentive to identify innovative and cost-effective methods to deliver care as it faces enormous challenges to respond to a rising demand for services combined with serious workforce challenges and quality of care issues. The use of EMRs holds promise for supporting the LTC industry in cost reductions, increased efficiency, and improved care quality. Indeed, an LTC staffing crisis exists and a potential solution is the use of IT to ease the excessive paperwork burden that takes nurses away from resident care $[18,19,20]$.

This study is significant in its approach to measuring work flow efficiencies through documentation of directly observed work process prior to and after initiation of the EMR system. While several articles reported that understanding work flow is an important component in the implementation and evaluation of EMR systems [12, 13, $16,17,21]$, there were no studies reporting the use of process flow analysis through direct observation as a method of evaluating the impact of the EMR. The direct observation and recording of steps in the work processes allowed the research team to get an accurate picture of exactly how the nurses' work processes changed after implementation of the EMR system. In line with studies reporting that nurses need greater involvement with the design of EMR systems [14, 22], the visual picture provided in the process flow analysis serves as a basis for nurses to contribute to the discussion about EMR system design and how it can be improved for greater effectiveness in the clinical setting. 
The visual picture of the work flow as affected by the EMR system can also provide a critical evaluation component related to the usability of the system. Usability has been identified as a key barrier to successful adoption and effective use of EMR systems $[14,16,17,23,24]$. The process flow chart provides a meaningful way to evaluate system usage and to identify areas for system improvements and work process efficiency.

Through the use of process flow analysis, this study demonstrated that the EMR can lead to a reduction in the number of steps required to complete several daily work processes allowing nurses the opportunity to dedicate more time to direct care of the facility's residents and thus contribute to improved quality of care. Nurses experienced greater efficiencies in their daily work by having immediate access to the resident's electronic record and avoiding the time required to find the paper record, which must be shared by several health professionals in the LTC setting.

Another finding observed by the researcher was related to maintaining parallel electronic and paper records in the LTC facility. It is not clear as to the facility's reason for maintaining a full paper record system in addition to the electronic system. However, in light of the need to increase efficiencies and eliminate dependency on redundant and ineffective paper-based systems [25], LTC facilities interested in implementing EMR systems will need to carefully evaluate the appropriate use of paper-based processes. Further research is needed to more fully document the impact of the EMR on cost savings, quality improvements, and nursing retention and satisfaction outcomes.

\section{CONCLUSION}

The Institute of Medicine [5] has reported the expanded use of IT has enormous potential to improve the safety, quality and efficiency of healthcare in the United States. With such strong support for IT acknowledged by healthcare experts, this study investigates if technology will provide staff members with the ability to do their work more efficiently and more accurately thus improving the quality of care and allowing staff members to spend more time in direct resident care. The findings of this study clearly demonstrate more efficient work processes after implementation of the EMR. Furthermore, the study provides a guide for further research about the relationship between IT and the quality of care for people living in LTC facilities.

\section{ACKNOWLEDGEMENTS}

The authors would like to acknowledge the Texas Department of Aging and Disability Services for financial support of this research study.

\section{REFERENCES}

[1] Kemper, P., Komisar, H.L., Alecxih, L. Long-term care over an uncertain future: What can current retirees expect? Inquiry, 2006, 42, 335-50.

[2] National Commission for Quality Long-Term Care. The long-term care workforce: Can the crisis be fixed? January, 2007. Institute for the Future of Aging Services. Available online at http://www.americanprogress.org/events/2007/07/pdf/workforce.pdf. 
[3] Cherry B., Carter M., Owen D., Lockhart, CL. Factors affecting electronic health record adoption in long-term care facilities. Journal for Healthcare Quality, 2008, 30(2), 37-47.

[4] Institute of Medicine. Key capabilities of an electronic health record system. Washington, D.C.: National Academies Press, 2003.

[5] Institute of Medicine. Crossing the quality chasm: A new health system for the $21^{\text {st }}$ Century. Washington, D.C.: National Academy Press, 2001.

[6] Chaudhry, B., Wang, J., Wu, S., Maglione, M., Mojica, W., Roth, E., et al. Systematic review: impact of health information technology on quality, efficiency, and costs of medical care. Annals of Internal Medicine, 2006, 144(10), 742-752.

[7] Goldzweig, C.L., Towfigh, A., Maglione, M., et al. Costs and benefits of health information technology: New trends from the literature." Health Affairs, 28(2): w282-93, 2009.

[8] DesRoches, C.M., Campbell, E.G., Rao, S.R., Donelan, K., Ferris, T.G., Jha, A., Kaushal, R., Levym D.E., Rosenbaum, S., Shields, A.E., and Blumenthal, D., Electronic health records in ambulatory care: A national survey of physicians. New England Journal of Medicine, 2008, 359: 50-60 July 3, 2008.

[9] Parente, S., \& McCullough, J. Health information technology and patient safety: Evidence from panel data. Health Affairs, 2009, 28(2), 357-360.

[10] Jha, A.K., DesRoches, C.M., Campbell, E.G., Donelan, K., Rao, S.R., Ferris, T.G., Shields, A., Rosenbaum, S., and Blumenthal, D. Use of electronic health records in U.S. hospitals. The New England Journal of Medicine, 2009, 360: 1628-38.

[11] Jha A.K., DesRoches, C.M., Shields, A., Miralles, P.D., Zheng, J., Rosenbaum, S., and Campbell, E.G. Evidence of an emerging digital divide among hospitals that care for the poor. Health Affairs, November 2009, 28: w1160-w1170.

[12] Mostashari, F., Tripathi, M., \& Kendall, M. A tale of two large community electronic health record extension projects. Health Affairs, 2009, 28(2), 345-356.

[13] Kaushal, R., Bates, D., Jenter, C., Mills, S., Volk, L., Burdick, E., et al. Imminent adopters of electronic health records in ambulatory care. Informatics in Primary Care, 2009, 17(1), 7-15.

[14] Stevenson, J., Nilsson, G., Petersson, G., \& Johanssson, P. Nurses' experience of using electronic patient records in everyday practice in acute/inpatient ward settings: A literature review. Health Informatics Journal, 2010, 16(1), 63-72.

[15] Greenhalgh, T., Stramer, K., Bratan, T., Byrne, E., Mohammad, Y., Russell, J. Introduction of shared electronic records: Multi-site case study using diffusion of innovation theory. BMJ. 2008; 337: a1786.

[16] Campbell, E. M., Guappone, K. P., Sittig, D. F., Dykstra, R. H., \& Ash, J. S. Computerized provider order entry adoption: implications for clinical workflow. Journal of General Internal Medicine, 2008, 24(1), 21-26.

[17] Kushniruk, A., Borycki, E., Kuwata, S., \& Kannry, J. Predicting changes in workflow resulting from healthcare information systems: ensuring the safety of healthcare. Healthcare Quarterly,2006, 9 Spec No, 114-118.

[18] Report to Congress. The Future supply of long-term care workers in relation to the aging baby boom generation. 2003. Report prepared by staff from the United States Department of Health and Human Services' Office of the Assistant Secretary for Planning and Evaluation, the Centers for Medicare and Medicaid Services.

[19] National Commission on Nursing Workforce for Long-Term Care. Act now for your tomorrow. 2005. Retrieved from http://www.ahca.org/research/workforce_rpt_050519.pdf.

[20] Institute of Medicine. Improving the quality of long-term care. Washington, DC: National Academy Press, 2001.

[21] Davidson, J. (2009). Electronic medical records: what they are and how they will revolutionize the delivery of resident care. Canadian Nursing Home, 2009, 20(3), 15-16. 
[22] Cherry, B., Ford, E.W., \& Peterson, L.T. (in press). Experiences with electronic health records: Early adopters in long-term care facilities. Health Care Management Review (tentatively Volume 36, number 3, 2011).

[23] Pearce, C., Shachak, A., Kushniruk, A., \& de Lusignan, S. Usability: a critical dimension for assessing the quality of clinical systems. Informatics in Primary Care, 2009, 17(4), 195-198.

[24] Kaplan, B. \& Harris-Salamone, K.D. Health IT success and failure: Recommendations from literature and an AMIA Workshop. JAMIA, 2009, 16:291-299.

[25] Campbell, E. M., Sittig, D. F., Ash, J. S., Guappone, K. P., \& Dykstra, R. H. Types of unintended consequences related to computerized provider order entry. Journal of the American Medical Informatics Association, 2006, 13(5), 547-556. 


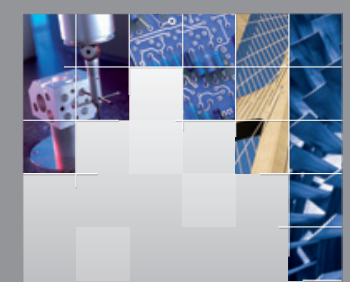

\section{Enfincering}
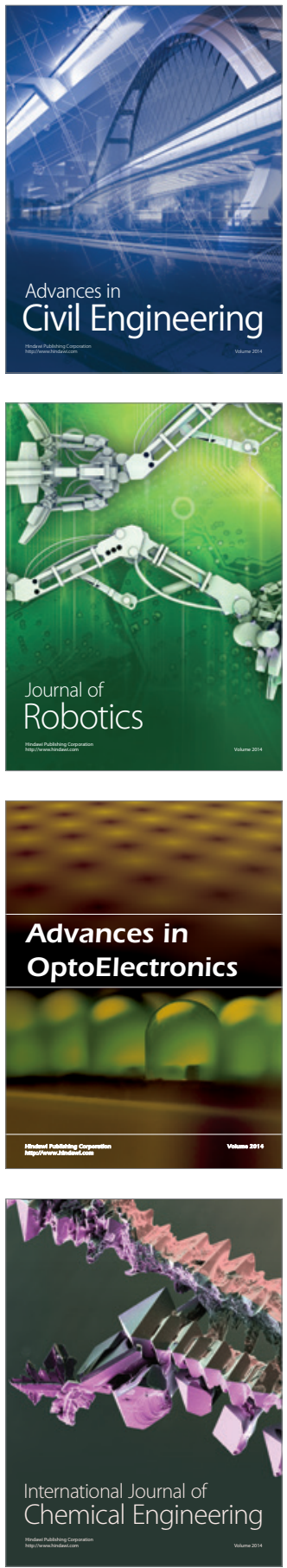

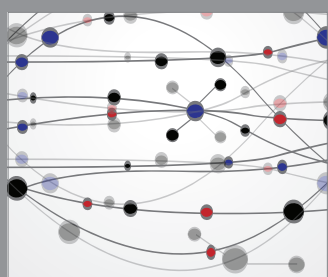

The Scientific World Journal

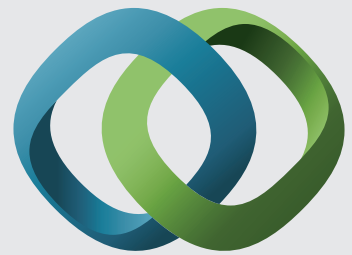

\section{Hindawi}

Submit your manuscripts at

http://www.hindawi.com
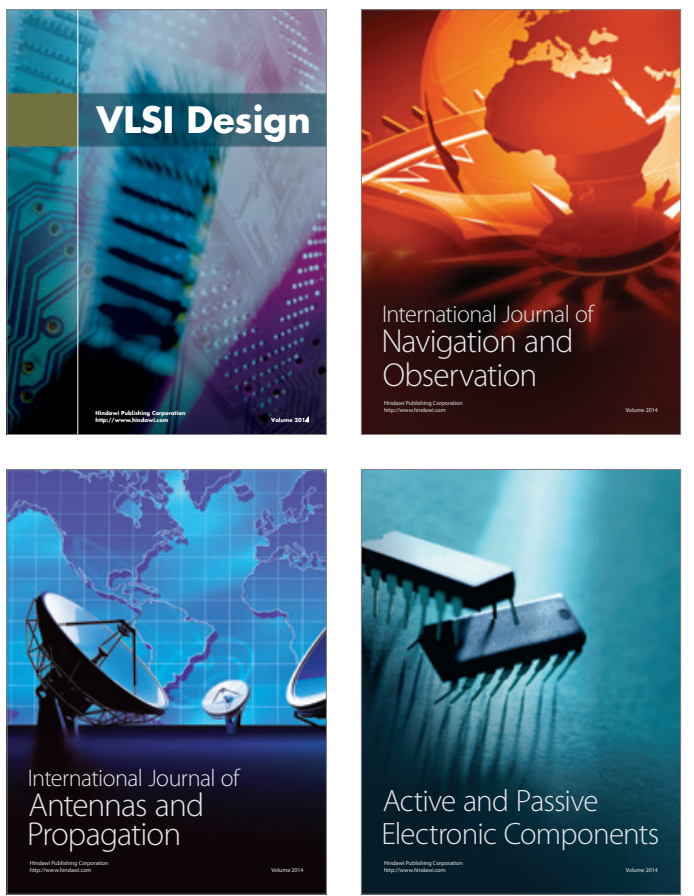
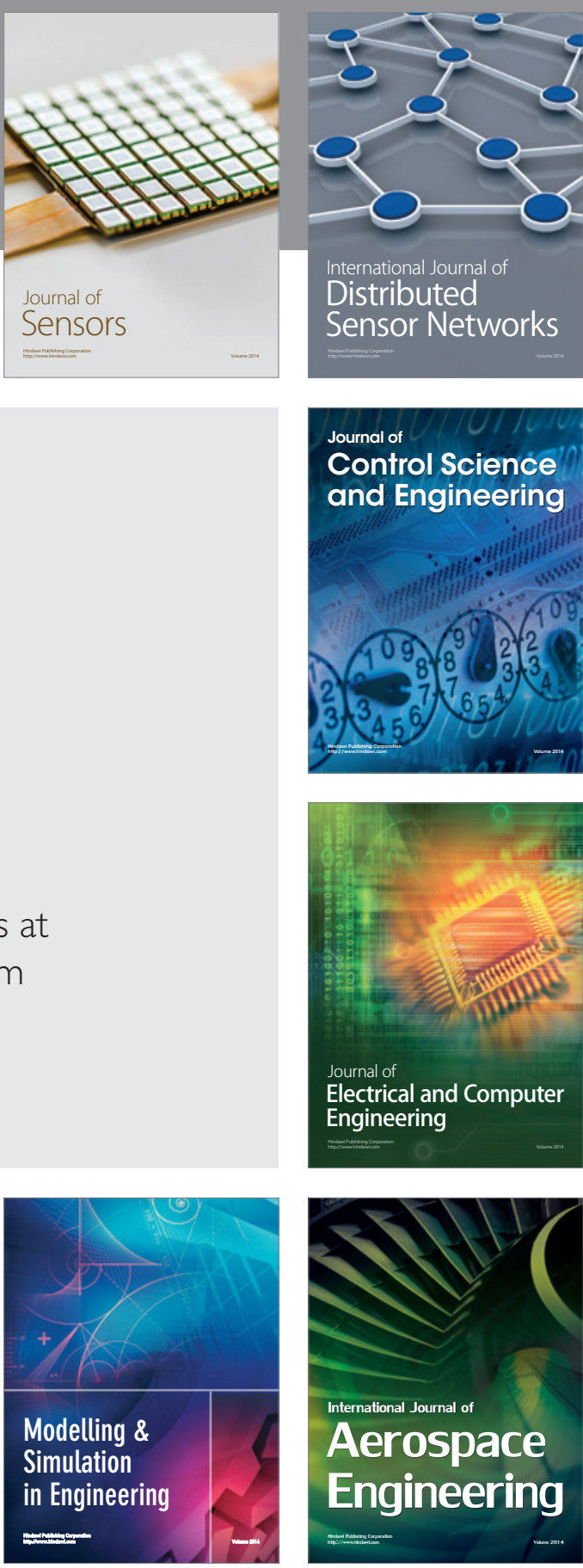

International Journal of

Distributed

Sensor Networks

Journal of

Control Science

and Engineering
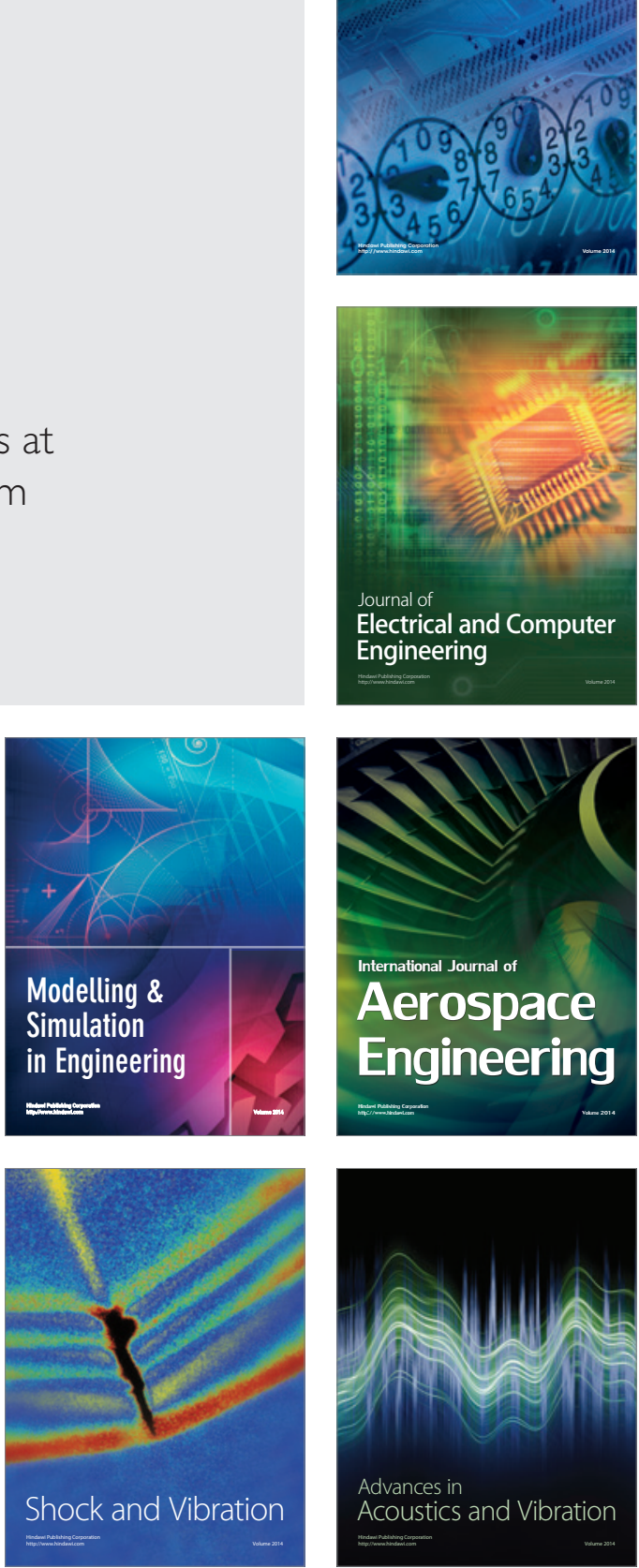